Article

\title{
Investigation of Surfactant AOT Mediated Charging of PS Particles Dispersed in Aqueous Solutions
}

\author{
Huiying Cao ${ }^{1}$, Baichao An ${ }^{2}$, Yong Wang ${ }^{1, *}$, Kun Zhou ${ }^{3}$ and Naiyan Lu ${ }^{4, *}$ \\ 1 School of Information and Engineering, Guangdong Medical University, Zhanjiang 524023, China \\ 2 School of Pharmacy, Guangdong Medical University, Zhanjiang 524023, China \\ 3 Center for Soft Condensed Matter Physics and Interdisciplinary Research, Soochow University, \\ Suzhou 215006, China \\ 4 State Key Laboratory of Food Science and Technology, Jiangnan University, Wuxi 214122, China \\ * Correspondence: ksh_wangyong@foxmail.com (Y.W.); lunaiyan@jiangnan.edu.cn (N.L.)
}

Received: 30 June 2019; Accepted: 24 July 2019; Published: 26 July 2019

\begin{abstract}
Nano/submicron particles can be activated by surfactants and aggregate at the air-water interface to generate and stabilize foams. Such systems have been applied extensively in the food, medicine, and cosmetic industries. Studying particle charging behavior in a particle/surfactant/water system is a fundamental way to understand the activation of the particle surface. This paper presents an investigation of the charging behavior of polystyrene (PS) particles dispersed in aqueous solutions of the surfactant sodium di-2-ethylhexylsulfosuccinate (AOT). The results showed that zeta potential of PS was related to the AOT concentration with two different concentration regions. Below the critical micelle concentration (CMC), the charging of PS particles was effected by AOT ions; while above the $\mathrm{CMC}$, it came from both AOT ions and AOT micelles. This behavior was different from that observed for PS in aqueous salt solutions. Additionally, the particle concentration and size were found to affect the zeta potential differently in the two AOT concentration regions. By analyzing these results, the charging mechanism of the PS/AOT/water system was revealed to be preferential adsorption. In summary, the study disclosed the internal connection between the PS charging in aqueous AOT solution and the activation of PS particles, as well as their influence to foam formation and stability.
\end{abstract}

Keywords: PS particles; AOT surfactant; charging behavior; activation; foam formation and stability

\section{Introduction}

Nano/submicron particle surfaces can be activated by the interactions between particles and surfactants in an aqueous solution. Activated particles aggregate at the air-water interface to cause foaming and foam stabilization [1-3]. This phenomenon has brought significant advances in both technology and industry, such as the preparation and assembly of new materials including so-called dry water [4], liquid marbles [5], colloidosomes [6], and anisotropic particles [7]. Industrial applications include oil recovery that is actualized by foam produced from the interaction between nanoparticles and mixed surfactant in a brine solution [8-10], and the fabrication of the porous ceramics and porous metals is accomplished using a particle-rich foams precursor [11]. The electrostatic interaction between the particles and the surfactant is believed to be a key factor in determining the surface activation of particles in such a system [8-12].

Usually, salt is typically used to control the charging of nano/submicron particles in aqueous solutions, whose mechanism has been clearly elucidated [13-15]. It is known that adding surfactants to aqueous solutions can influence the charging of particles by adsorption mechanisms $[16,17]$. With this knowledge, charge-induced crystallization of such particles is achieved using strongly 
adsorbing fluorinate-based ionic surfactants [18]. Yamanaka et al. [19] also uses a cationic surfactant, cetylpyridinium chloride (CPC), to manipulate the polarity and magnitude of colloid surface charge, thereby leading to cluster formation in various aqueous suspensions of colloids. Meanwhile, the surfactant also influences the particle surface chemical characteristics, i.e., the activation of the surface, which is a decisive factor for colloidal particles in terms of the foam formation and the stability of foams $[1,20,21]$. This activation can be affected by the particle charging caused by surfactants. However, relative research to disclose their inner connections is still not far enough, and more work is needed.

Sodium di-2-ethylhexylsulfosuccinate (AOT), an anionic surfactant with two alkyl chains that is widely used in chemical, biological, pharmaceutical, and nanotechnology applications, dissolves easily in both water and nonpolar solvents. In water, an AOT molecule dissociates into a cation and an anion, i.e., a sodium cation and an AOT anion composed of a negatively charged head group and a two hydrophobic alkyl chain tails. Above the critical micelle concentration (CMC), AOT ions can aggregate and form micelles in deionized water [22,23], the size of which is close to $20 \mathrm{~nm}$, much larger than the size of simple ions $(<<1 \mathrm{~nm})$ [23]. The measured CMC values of AOT in pure water vary from 0.1 to $2.2 \mathrm{mM}[22,24]$.

In a polar solution, usually, there are two typical basic charging mechanisms for nano/submicron particles: Namely, preferential adsorption of a charged species to the particle surface, and dissociation of surface groups. Usually, charging mechanisms are studied in solutions by analyzing the electrophoretic mobility or zeta potential of the particles under different dispersion parameters, such as salt/surfactant concentrations, particle concentrations, and particle sizes [1,20]. Among these, analyzing the effect of salt/surfactant concentrations on particle charging is the most common method. Although there are relatively fewer, the studies on the effects of the particle concentration on electrophoretic mobility or zeta potential of the particles in solution, this is indeed a suitable way to reveal the charging behavior of the particles [21,22]. In addition, examining the influence of the size of a particle on its electrophoretic mobility or zeta potential is also a good way to determine the charging mechanism in solution [23].

In this paper, the zeta potential of PS particles was studied as a function of AOT concentration, PS particle concentration, and particle size by measuring electrophoretic mobility using phase angle light scattering (PALS). The variation in zeta potential was divided into two different phases, associated with the changes in the morphology of AOT in these concentration regions, i.e., AOT ions below the $\mathrm{CMC}$ region, and AOT micelles and AOT ions above the CMC region. Additionally, the experimental results revealed preferential adsorption as the charging mechanism of the PS/AOT/water system. The results also explained the effect of PS charging on the activation degree of particle surfaces, and predicted the foaming behavior of the PS/AOT/water system in two AOT concentration regions. The aim of this work is to better understand the charging behavior of nano/submicron particles in an aqueous surfactant system, as well as the influence of the electrostatic interaction between them on the activation of particle surfaces in such an environment, so as to apply them to relevant technologies and industries.

\section{Experimental Section}

\subsection{Materials and Methods}

PS particles with diameters of 141, 311, and $535 \mathrm{~nm}$ were collected from the Technical Institute of Physics and Chemistry, CAS, Beijing, China. These particles were originally received as a dispersion in deionized water, therefore, a dehydration process was used to obtain dry particles. This involved a multistage solvent swap using ethanol as an intermediate solvent, followed by vacuum drying at $30^{\circ} \mathrm{C}$ and storage in a loft drier. Figure 1 shows a scanning electron microscopy (SEM; Quanta 200, FEI, Waltham, MA, USA) image of the dried PS particles, demonstrating their good dispersity and morphology. The surfactant AOT (99\% purity, Sigma-Aldrich Company, St. Louis, MI, USA) was used 
as received. Deionized water with a resistance of $18.2 \mathrm{M} \Omega \mathrm{cm}$ and a $\mathrm{pH}$ of 6.7 at $25^{\circ} \mathrm{C}$ was obtained from a deionized water system (LDD-01, Ludao, Shanghai, China).
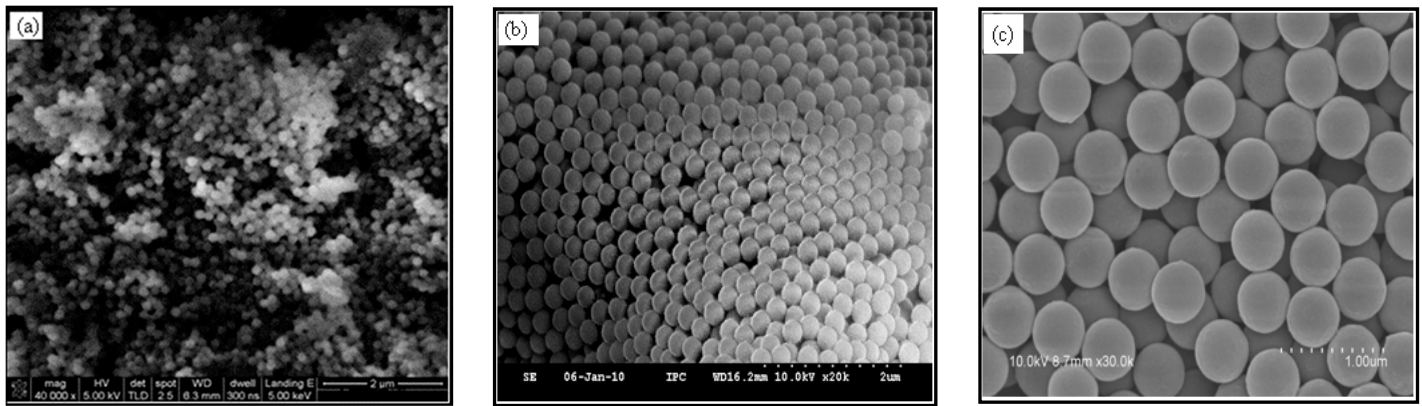

Figure 1. SEM image of PS particles dispersed in pure water after drying for particle sizes of (a) $141 \mathrm{~nm}$, (b) $311 \mathrm{~nm}$, and (c) $535 \mathrm{~nm}$.

Dispersions of AOT in deionized water with concentrations of $0.01-10 \mathrm{mM}$ were first prepared under stirring with a constant temperature magnetic stirrer (85-2, Changzhou, China) at $1000 \mathrm{rpm}$ for 2-5 min. After AOT was dispersed completely in water, the dried PS particles were then weighed and added to these aqueous surfactant solutions. The samples were sonicated at $40 \mathrm{kHz}$ for $40 \mathrm{~min}$ until they formed a well-mixed solution. Subsequently, these samples were sealed and equilibrated for more than $12 \mathrm{~h}$ before measuring their conductivity and electrophoretic mobility.

\subsection{Measurements of Conductivity and $p H$}

We used a conductivity meter (Mettler, Seven2Go pro, Columbus, OH, USA) to measure the conductivities of the AOT/water and PS/AOT/water systems, for which the background conductivity of deionized water was less than $0.1 \mu \mathrm{s} / \mathrm{cm}$. The relationship between conductivity and AOT concentration is shown in Figure 2. For the AOT/water system, the conductivity values were a few $\mu \mathrm{s} / \mathrm{cm}$ in the AOT concentration range of $0.001-0.1 \mathrm{mM}$. When AOT concentration approached the CMC $[18,20]$, the magnitude of the conductivity was found to increase rapidly, and reached $134 \mu \mathrm{s} / \mathrm{cm}$ at an AOT concentration of $10 \mathrm{mM}$. However, at the same salt concentration, the conductivity value was only a few $\mu \mathrm{s} / \mathrm{cm}$ [25]. Similarly, after the addition of PS to the aqueous AOT solutions, the conductivity values ranged from 24 to $58 \mu \mathrm{s} / \mathrm{cm}$, even at low AOT concentrations $(0.001-0.1 \mathrm{mM})$, and at high AOT concentration, the value reached nearly $200 \mu \mathrm{s} / \mathrm{cm}$.

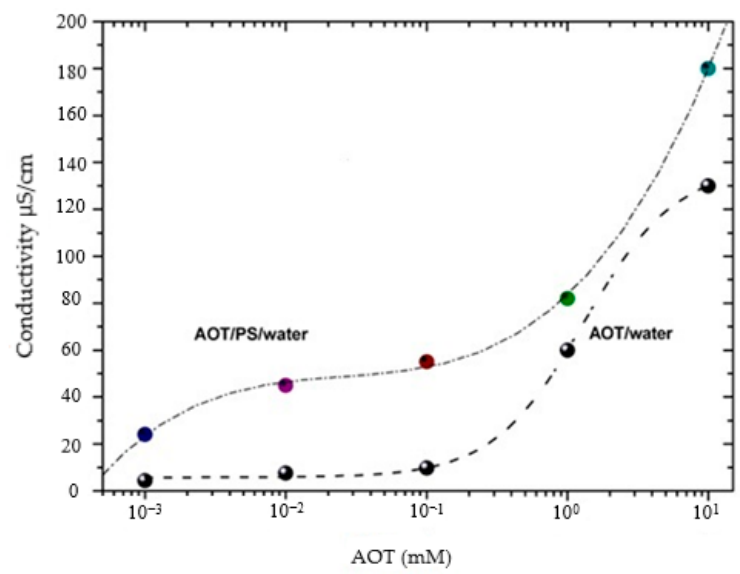

Figure 2. Conductivities of the AOT/water and PS/AOT/water systems. The conductivity of deionized water as the measured background was less than $0.1 \mu \mathrm{s} / \mathrm{cm}$. The AOT concentration ranged from 0.001 to $10 \mathrm{mM}$. AOT: Sodium di-2-ethylhexylsulfosuccinate; PS: Polystyrene. 
Using a $\mathrm{pH}$ meter (Mettler, SevenCompact), the $\mathrm{pH}$ values of the aqueous AOT solutions with different AOT concentrations were measured. The relationship between $\mathrm{pH}$ and AOT concentration is shown in Figure 3. From the data, the aqueous AOT solutions were found to be slightly acidic, while the $\mathrm{pH}$ value was mostly independent of AOT concentration.

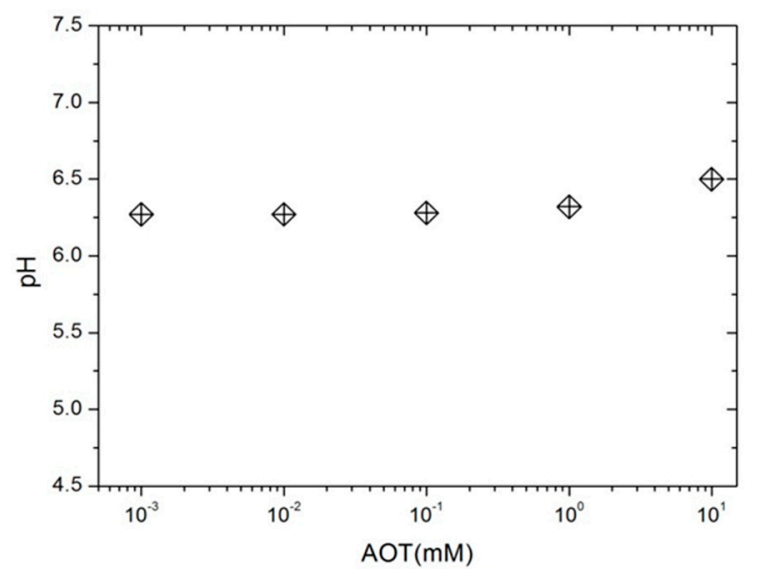

Figure 3. Relationship between $\mathrm{pH}$ and AOT concentration in aqueous AOT solution.

\subsection{Electrophoretic Mobility Measurements}

The electrophoretic mobilities of the samples were measured using PALS (Brookhaven Zeta PALS with a platinum electrode separation of $3.6 \mathrm{~mm}$ ) by applying an electric field of $1 \mathrm{~V} / \mathrm{cm}$ at a $2 \mathrm{~Hz}$ sinusoidal frequency. The PS particles in the $\mathrm{PS} / \mathrm{NaCl} /$ water and $\mathrm{PS} / \mathrm{AOT} /$ water systems were found to move in the opposite direction of the applied electric field. One hundred field cycles were conducted, and each sample was measured three times under the same electric field and temperature $\left(25^{\circ} \mathrm{C}\right)$. In all the above measurements, the range of AOT concentrations was set as $0.001-10 \mathrm{mM}$. The upper concentration limit was chosen as $10 \mathrm{mM}$ because AOT easily causes foaming in water, making the measurement of the electrophoretic mobility difficult at higher concentrations.

\section{Results}

Electrophoretic mobility of PS particles, both in aqueous solution of sodium chloride and in AOT aqueous solution, was measured. It was found PS particles had negative charges by measuring their electrophoretic mobility by PALS in both aqueous systems. In aqueous solutions, zeta potential is given by the Smoluchowski expression, $\mu=\zeta \varepsilon_{0} \varepsilon_{\mathrm{r}} / \eta$ [26], where $\mu$ is the mobility of a charged particle; $\varepsilon_{0}=1, \varepsilon_{\mathrm{r}}=80$ are the vacuum permittivity and relative permittivity of water, respectively; $\eta=0.85 \mathrm{mPa} \cdot \mathrm{s}$ represents the viscosity of an aqueous solution at $25^{\circ} \mathrm{C}$; and $\zeta$ is the zeta potential一the zeta potential of a PS particle was calculated based on its electrophoretic mobility $\mu$ in such systems. Figure 4 shows the zeta potential of PS particles in aqueous dispersion as a function of the $\mathrm{NaCl}$ concentration. The zeta potential $|\zeta|$ increased with the increase of $\mathrm{NaCl}$ concentration over the concentration of range. Below a salt concentration of $0.1 \mathrm{mM}$, the zeta potential showed a very slow increase with increasing salt concentration. However, a rapid increase was observed at approximately $0.1 \mathrm{mM}$. Beyond $0.1 \mathrm{mM}$, the zeta potential showed a steady proportional increase with the salt concentration. Therefore, different from the negative charges caused by the dissociation of the surface carboxyl of PMMA particles in aqueous solution [27], the increased negative zeta potential of the PS particles likely stems mainly from the adsorption of chloride ions from salt solution. 


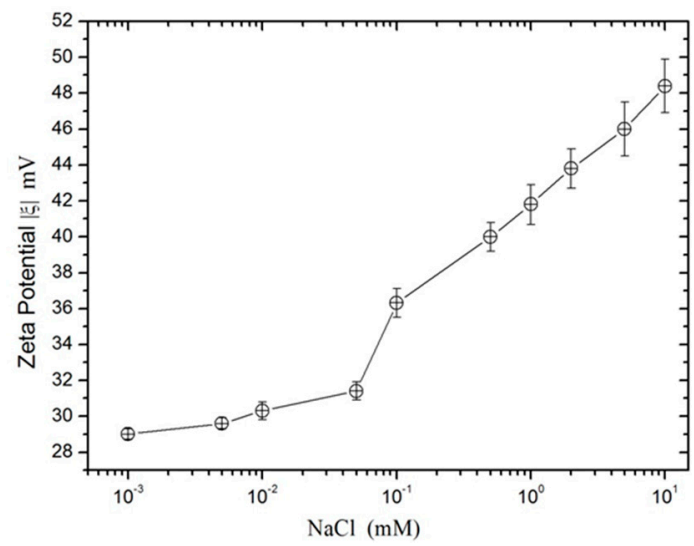

Figure 4. Zeta potential in aqueous dispersions at various salt concentrations. The particle concentration was $0.01 \%$, and the particle size was $535 \mathrm{~nm}$.

Similarly, the zeta potential of the PS/AOT/water system was also calculated using the equation $\mu=\zeta \varepsilon_{0} \varepsilon_{\mathrm{r}} / \eta$. Figure 5 shows the relationship between the zeta potential and the AOT concentration in the range of 0.001 to $10 \mathrm{mM}$. The zeta potential increased throughout the whole concentration range. The charging behavior consisted of three regions. At surfactant concentrations below the $\mathrm{CMC}$, from 0.001 to $0.005 \mathrm{mM}$ (Region I), the zeta potential increased relatively slowly with the AOT concentration, which was similar to the behavior of the aqueous salt solution in this range; and from 0.005 to $0.5 \mathrm{mM}$ (Region II), a rapid increase of the zeta potential with AOT concentration occurred, and their relationship could be described with a convex curve. In contrast, the salt concentration for the rapid rise of zeta potential was more than $0.5 \mathrm{mM}$. At surfactant concentrations above the $\mathrm{CMC}$, from 0.5 to $10 \mathrm{mM}$ (Region III), and especially at concentrations greatly above the CMC, the zeta potentials continued to increase with the AOT concentration, but the curve became concave, indicating that the increase of the zeta potential with AOT concentration begins to slow again. This behavior differs from the nearly linear growth of the zeta potential in the 0.1-10 $\mathrm{mM}$ range in Figure 4.

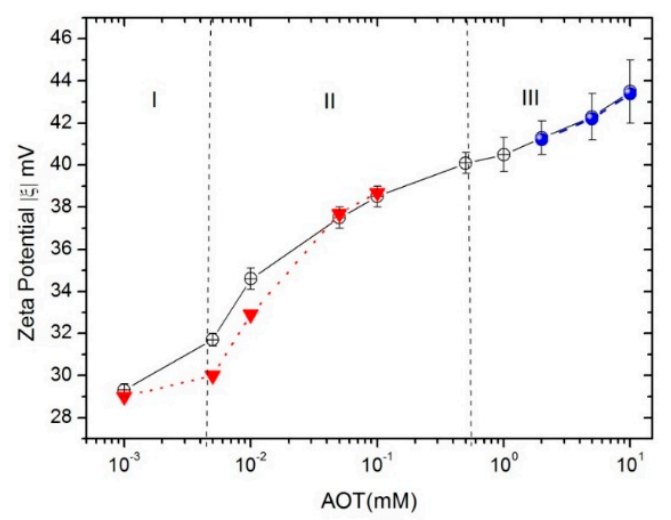

Figure 5. Zeta potential of PS at different AOT concentrations. The particle concentration was $0.01 \%$, and the particle size was $535 \mathrm{~nm}$. Black solid line and symbol indicate measured values. Red dotted line and symbol indicate calculated values below the CMC. Blue dashed line and symbol indicated calculated values above the CMC. CMC: Critical micelle concentration.

Quantitatively, below the $\mathrm{CMC}$, the relationship between the zeta potential and the AOT concentration can be described approximately by the expression $\left.|\zeta| \approx 28.63+\left|\zeta_{\mathrm{CMC}}\right|([\mathrm{AOT}]) /[\mathrm{CMC}]\right)^{\alpha}$ $(\mathrm{mV})$, where 28.63 is the absolute zeta potential value of a PS particle with a size of $535 \mathrm{~nm}$ in pure water (this value is independent of the particle concentration but dependent on the particle size), [AOT] and $[\mathrm{CMC}]$ denote the surfactant concentration and the critical micelle concentration, respectively, $\left|\zeta_{\mathrm{CMC}}\right|$ is the zeta potential at the $\mathrm{CMC}$, and $\alpha$ is a coefficient less than 1 that is related to AOT concentration. 
The fitting of the experimental data with this expression is plotted as a red symbol and line in Figure 5, where $\left|\zeta_{\mathrm{CMC}}\right|$ is set as $40 \mathrm{mV}$, [CMC] is $1 \mathrm{mM}, \alpha=2 / 3$ is chosen for $0.001 \mathrm{mM} \leq[\mathrm{AOT}] \leq 0.005 \mathrm{mM}$, $\alpha=1 / 2$ is used for $0.005 \mathrm{mM}<[\mathrm{AOT}] \leq 0.05 \mathrm{mM}$, and $\alpha=3 / 5$ was for $0.05 \mathrm{mM} \leq[\mathrm{AOT}]<0.5 \mathrm{mM}$. Above the $\mathrm{CMC}$, the curve of the zeta potential and AOT concentration could be approximately described using the expression $|\zeta| \approx 28.63+\beta([\mathrm{AOT}]-[\mathrm{CMC}])^{\frac{3}{2}}$, where $\beta$ is a coefficient greater than zero that is associated with AOT concentration. The experimental data were fitted with this expression; the result is plotted in Figure 5 as a blue symbol and line, where the fitting interval is $1 \mathrm{mM}<[\mathrm{AOT}] \leq 10 \mathrm{mM}$. However, fitting using two expressions fails for the experimental data in the interval of $0.5-1 \mathrm{mM}$. Instability of the AOT micelles initially formed by the molecules in this interval $[22,24]$ is possibly responsible for this failure.

We also studied the effect of particle concentration on the zeta potential; the results are shown in Figure 6. Due to the tendency of the PS particles to foam in water, it was difficult to measure the electrophoretic mobility at higher particle concentrations because the amount of foam would increase with particle concentration, therefore, particle concentrations of $0.01 \%, 0.02 \%$, and $0.03 \%$ were chosen for the measurements. It can be seen that the zeta potential of PS was independent of the particle concentration in the absence of a surfactant. When the AOT concentration was increased from 0 to $0.01 \mathrm{mM}$ (below the $\mathrm{CMC}$, indicated by blue lines and symbols), the zeta potential curve began to decay slightly at particle concentrations of $0.02 \%$ and $0.03 \%$. In contrast, at AOT concentrations beyond $0.1 \mathrm{mM}$ (near the $\mathrm{CMC}$, indicated by green lines and symbols), the zeta potential began to increase with the particle concentration, but not in a linear fashion. Moreover, with the surfactant concentration increasing further (beyond the CMC, indicated by red lines and symbols), the degree of the zeta potential increased with the particle concentration became more obvious. In the aqueous salt solution, similar results have been found for the relationship between electrophoretic mobility and particle density; however, the zeta potential in this system increases linearly with particle concentration at high salt concentrations [13].

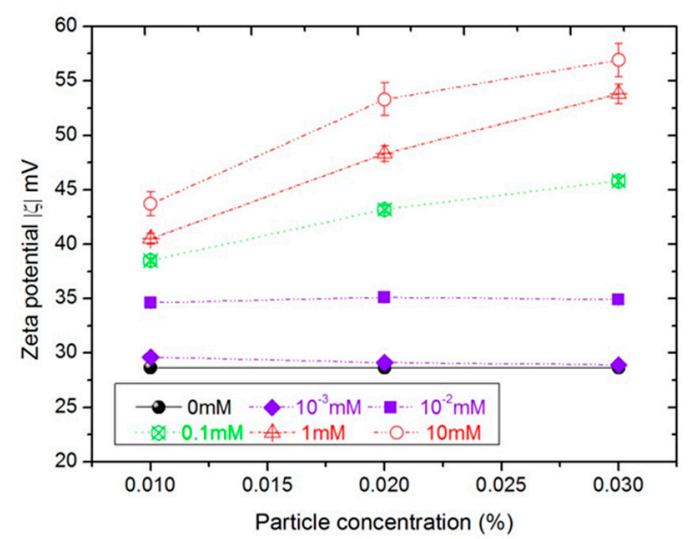

Figure 6. The zeta potential as a function of particle concentration at different AOT concentrations and a PS particle size of $535 \mathrm{~nm}$.

The charges on particle surfaces have been verified to scale up with the size of the particles in pure water [13]. Therefore, we analyzed the effect of particle size on the zeta potential at relatively high AOT concentrations, i.e., $0.1-10 \mathrm{mM}$, as shown in Figure 7. In general, the absolute value of the zeta potential was found to increase with particle size. For an AOT concentration of $0.1 \mathrm{mM}$, the curve of the zeta potential as a function of size was approximately a straight line. From this, we can infer that a straight line will be expected for an AOT concentration of less than $0.1 \mathrm{mM}$. When the AOT concentration approached or exceeds the $\mathrm{CMC}$, although the zeta potential still increased with increasing particle size, the relationship was not linear. Instead, the slope of the line increased with increasing particle size. By comparing the difference in the zeta potential values of the 141 and $535 \mathrm{~nm}$ particles, it was found that the zeta potential increased with the particle size when the AOT concentration increased 
from 1 to $10 \mathrm{mM}$. The relationship between the zeta potential and particle size in the AOT-containing solutions was different from that observed in low or high concentration aqueous salt solutions, where the surface potential is basically independent of the particle size [14,28].

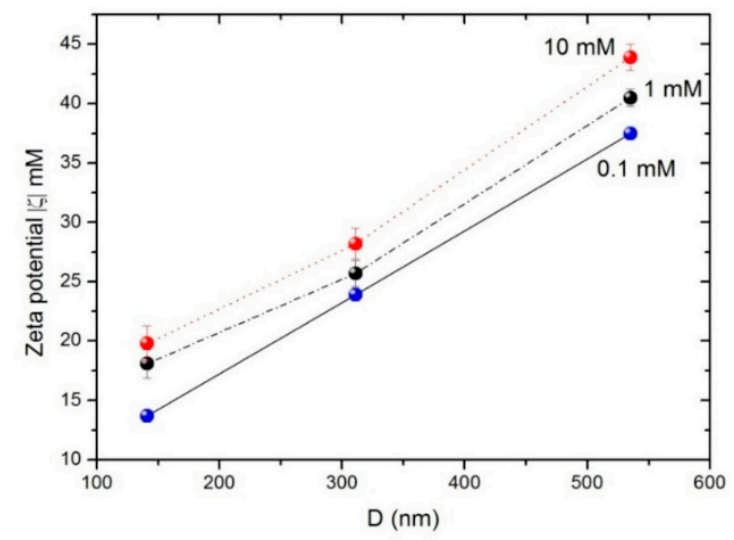

Figure 7. The zeta potential as a function of particle diameter with AOT concentration from 0.1 to $10 \mathrm{mM}$ and a PS particle concentration of $0.01 \%$.

\section{Discussion}

Usually, if the surface charges of particles originate from the dissociation of surface groups, and surrounded by AOT molecules, the particles will move slowly, therefore, reducing the overall conductivity instead of enhancing it. However, a surprising increase of the conductivity of the PS/AOT/water system is observed in Figure 2. It was found that the number of carboxyl groups on the surface of PS particles was negligible; therefore, the charges of the particles should originate from other charged species such as $\mathrm{OH}^{-}$ions rather than carboxyl groups, AOT ions, and/or charged AOT micelles by adsorption in solution. Therefore, with the increasing of AOT concentration, the number of charges adsorbed on the surface of PS particles increases enough to surpass the reduction effect caused by the layer of surfactant molecules.

Comparing Figure 4 to Figure 5, the charging behavior of PS particles in aqueous AOT solution is somewhat similar to their behaviors in salt solutions, including that the zeta potential increases with increasing concentration of the charge control agent and the magnitude of the zeta potentials. As seen in Figure 3, the $\mathrm{pH}$ of the AOT solution remains at around 6.3 with the varying AOT concentration; therefore, PS charging in the AOT solution occurred in a near-neutral environment, similar to that in the salt solution, which is a possible cause for the similarity of PS charging behavior in the two systems. Nevertheless, two obvious differences between the systems were observed: Below the CMC of AOT, the effect of the AOT ions on PS charging was stronger than that of the salt ions; however, beyond the $\mathrm{CMC}$ of $\mathrm{AOT}$, a concave increase in the charge of PS with AOT concentration was observed, rather than the near-linear increase seen in salt solution, which was attributed to the participation of AOT micelles. Therefore, the PS charging process is more complicated in an aqueous AOT solution than in a salt solution.

The PS charging behavior in an aqueous AOT solution can be described by three regions, as shown in Figure 5. In Region I, the fixed number of the particle surface charges should arise mainly from $\mathrm{OH}^{-}$ions; the other surface charges could be by anions derived either from AOT ions or from the dissociation of surface groups. We infer that these anions originate from AOT ions, since increasing the AOT concentration provides more AOT ions to adsorb on the surface of the particles, resulting in a proportional increase of the zeta potential (see Figure 8a); conversely, if the charges had originated from the dissociation of surface groups, zeta potential would have remained unchanged under a fixed particle concentration. Therefore, an approximately linear relationship is observed between the zeta potential and AOT concentration in Region I. In Region II, with the number of AOT ions increasing and the onset of AOT micelle formation, more surface sites of the particle are occupied by AOT ions 
and some AOT semi-micelles, leading to a continued rapid increase in the zeta potential. However, in the charging process of Region III, due to the aggregation of some fractions of AOT ions into micelles, the number of AOT ions occupying the surface sites of particles will not increase proportionally with AOT concentration as it does in Region II. Consequently, the surface sites of the particle are occupied by both AOT micelles and ions (see Figure 8b), which may be the cause of the slower increase in the zeta potential of PS with the further addition of AOT.
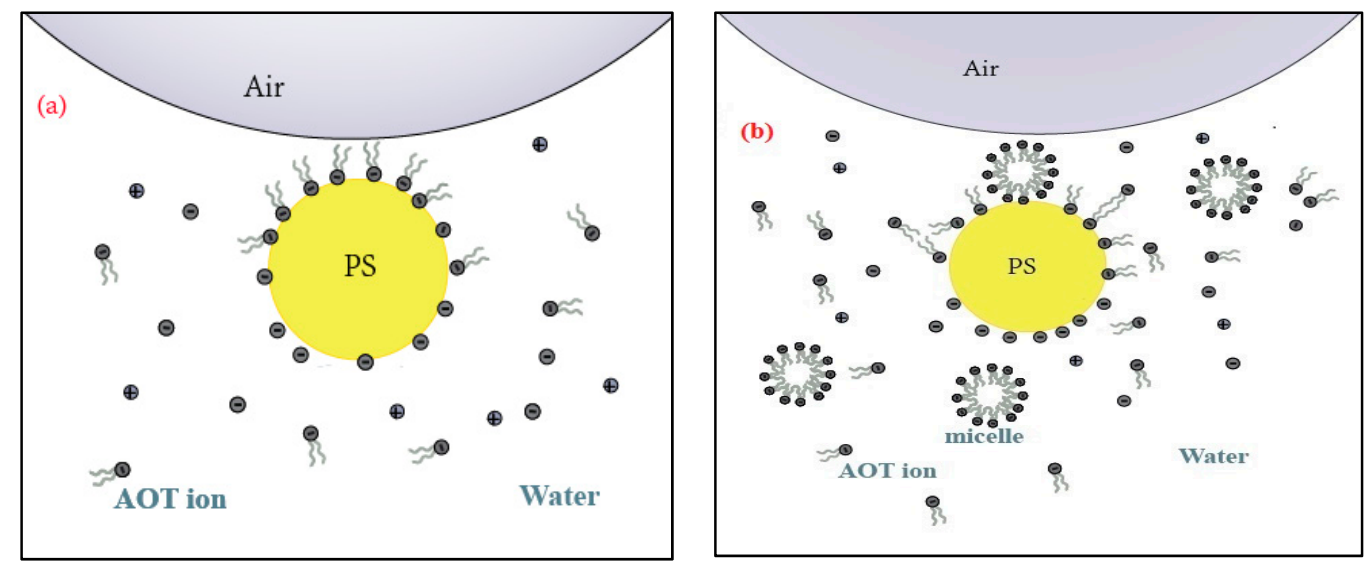

Figure 8. Schematic representation of the charging and surface activation of a PS particle in aqueous AOT solution: (a) At low AOT concentration (less than $0.1 \mathrm{mM}$ ) and (b) at high AOT concentration.

As shown in Figure 6, at low AOT concentrations $(0-0.1 \mathrm{mM})$, the zeta potential of the particles is nearly independent of the particle concentration. At high AOT concentrations $(0.1-10 \mathrm{mM})$, the zeta potential of the particles was increased with the particle concentration. Moreover, at the same AOT concentration, the zeta potential increased with the particle concentration, which seems counterintuitive. In fact, since the concentration of micelles and ions is sufficient to occupy the surface sites, the surface of a particle reaches adsorption saturation at low particle concentrations. Furthermore, double-layer adsorption on the particle surface may occur, leading to a decrease of the zeta potential. However, with the increase of the particle number, this double layer would disappear gradually, affording an increase of the zeta potential with particle concentration at a constant AOT concentration. Otherwise, if the particle charging mechanism is explained via the dissociation of surface groups, contradicting results would be obtained, as shown in Figures 2, 5 and 7. Similarly, below $0.1 \mathrm{mM}$ in Figure 7, the particle surface sites are occupied mainly by the $\mathrm{OH}^{-}$ions in water, with only a relatively small number being occupied by AOT ions. Consequently, the surface charge was directly proportional to the particle size. However, above $0.1 \mathrm{mM}$, the particle surface sites are occupied mainly by charged AOT micelles and AOT ions rather than $\mathrm{OH}^{-}$ions. Therefore, with the concentration of AOT ions and AOT micelles increasing, more sites are occupied, leading to the increase of the zeta potential. This is the reason that the zeta potential for the $535 \mathrm{~nm}$ particles showed greater change between 10 and $1 \mathrm{mM}$ than the $110 \mathrm{~nm}$ particles in the same AOT concentration region.

As discussed in the above analysis of the relationship between the zeta potential and the AOT concentration, particle concentration, and particle size, the charging mechanism of the PS/AOT/water system is obviously the preferential adsorption of AOT ions or charged negative micelles, rather than dissociation of surface groups. Otherwise, with a fixed particle concentration, the zeta potential would be independent of the AOT concentration in Figure 5; at low surfactant concentration region, the zeta potential would increase with particle concentration in Figure 6; moreover, the zeta potential would also have a linear relationship with particle size and be independent of the AOT concentration in Figure 7. Furthermore, the experimental results are found to be agreement with the corresponding numerical simulations for a charging model based on the preferential adsorption mechanism [29]. 
The adsorption of AOT ions or charged micelles on the particle surfaces influenced the foaming behavior of the PS/AOT/water system. When the AOT concentration was increased from 0 to $0.1 \mathrm{mM}$, the activation of the particle surfaces was strengthened with the zeta potential increasing. This is because the PS particle surfaces preferentially adsorbed negatively charged AOT ions from the solution; the hydrophilic head groups are adsorbed on the surface of particles and the hydrophobic tails are oriented outwards. This results in the particle surfaces becoming more hydrophobic, as shown in Figure $8 \mathrm{a}$. Therefore, the negatively charged particles are readily adsorbed at the air-water interface in aqueous solution, increasing foam formation and stability of the systems at these AOT concentrations. This is verified in $\mathrm{CaCO}_{3} / \mathrm{AOT} /$ water and $\mathrm{TiO}_{2} / \mathrm{AOT} /$ water systems [21,30]. However, as the AOT concentration was increased above the $\mathrm{CMC}$, especially at much higher concentrations, the activation of the particle surfaces began to weaken with the growth of zeta potential slowing down, as a result of the reduction of the hydrophobicity of the surfaces. This is due to the adsorption of negatively charged micelles by some of the surface sites, or due to association between the carbon chains of AOT ions, which causes the hydrophilic head groups to be oriented towards water, as shown in Figure 8b. Thus, this process may result in particles detaching from the air-water interface and reduce the foam stability at high AOT concentrations. This speculation will be examined in our next work.

\section{Conclusions}

Using a conductivity meter and a $\mathrm{pH}$ meter, the conductivity and $\mathrm{pH}$ values of an aqueous AOT solution were examined. The results showed that the conductivity was divided into two regions based on the AOT concentration. At concentrations of 0.001-0.1 mM (below the CMC), the conductivity was nearly independent of the AOT concentration; however, at concentrations of $0.1-10 \mathrm{mM}$ (above the $\mathrm{CMC}$ ), the conductivity increased with increasing AOT concentration. A near-neutral $\mathrm{pH}$ was observed over a range of different AOT concentration in water, which was possibly the underlying reason for the similarity between PS charging behavior being presented in the aqueous AOT solution and the salt solution.

Using phase angle light scattering (PALS), the electrophoretic mobility was measured and the zeta potential was calculated as a function of AOT concentration, PS particle concentration, and particle size. The zeta potential increased with the increase of AOT concentration over the whole concentration range. Below the $\mathrm{CMC}$, the rapid increase in the zeta potential stemmed from the AOT ions. Above the $\mathrm{CMC}$, the increase of the zeta potential was slower, due to the coexistence of AOT micelles and AOT ions. AOT micelles were speculated to be the main cause for the difference of PS charging in the aqueous AOT solution and in the aqueous salt solution. The effect of particle concentration on the zeta potential was also related to the AOT concentration. Below the CMC, the zeta potential was weakly correlated with the particle concentration. Above the CMC, the zeta potential increased with particle concentration. Similarly, the relationship between the zeta potential and the particle size was modulated by the AOT concentration; i.e., a linear relationship was observed below the CMC, while a non-linear increase was observed above the CMC. All these results indicate that the charging mechanism of the PS/AOT/water system was preferential adsorption, and revealed the underlying association between the activation of the particle surfaces and particle charging.

Author Contributions: Methodology, H.C.; Experiment, B.A. and K.Z.; Data Analysis, Y.W. and H.C.; Writing-Original Draft, H.C. and Y.W.; Writing-Review and Editing, N.L.; Funding Acquisition, H.C., N.L. and Y.W.

Funding: This research was funded by the Natural Science Foundation of Guangdong Province (2015A030310178) and the National Natural Science Foundation of China (31401589).

Acknowledgments: We acknowledge Mandal and his team provided research motivation for this manuscript. We also acknowledge an unknown master for his help in the experiment.

Conflicts of Interest: The authors declare no conflict of interest. 


\section{References}

1. Binks, B.P. Particles as surfactants-similarities and differences. Curr. Opin. Colloid Interface Sci. 2002, 7, $21-41$. [CrossRef]

2. Du, Z.P.; Bilbao-Montoya, M.P.; Binks, B.P.; Dickinson, E.; Ettelaie, R.; Murray, B.S. Outstanding stability of particle-stabilized bubbles. Langmuir 2003, 19, 3106-3108. [CrossRef]

3. Dickinson, E. Biopolymer-based particles as stabilizing agents for emulsions and foams. Food Hydrocoll. 2017, 68, 219-231. [CrossRef]

4. Forny, L.; Pezron, I.; Saleh, K.; Guigon, P.; Komunjer, L. Storing water in powder form by self-assembling hydrophobic silica nanoparticles. Powder Technol. 2007, 171, 15-24. [CrossRef]

5. McHale, G.; Newton, M.I. Liquid marbles: Principles and applications. Soft Matter 2011, 7, 5473. [CrossRef]

6. Dinsmore, A.D.; Hsu, M.F.; Nikolaides, M.G.; Marquez, M.; Bausch, A.R.; Weitz, D.A. Colloidosomes: Selectively permeable capsules composed of colloidal particles. Science 2002, 298, 1006-1009. [CrossRef] [PubMed]

7. Velev, O.D. A class of microstructured particles through colloidal crystallization. Science 2000, 287, 2240-2243. [CrossRef] [PubMed]

8. Bera, A.; Ojha, K.; Mandal, A. Synergistic effect of mixed surfactant systems on foam behavior and surface tension. J. Surfactants Deterg. 2013, 16, 621-630. [CrossRef]

9. Kumar, S.; Mandal, A. Investigation on stabilization of $\mathrm{CO}_{2}$ foam by ionic and nonionic surfactants in presence of different additives for application in enhanced oil recovery. Appl. Surf. Sci. 2017, 420, 9-20. [CrossRef]

10. Kumar, N.; Gaur, T.; Mandal, A. Characterization of SPN Pickering emulsions for application in enhanced oil recovery. J. Ind. Eng. Chem. 2017, 54, 304-315. [CrossRef]

11. Gonzenbach, U.T.; Studart, A.R.; Tervoort, E.; Gauckler, L.J. Ultrastable particle-stabilized foams. Angew. Chem. Int. Ed. 2006, 45, 3526-3530. [CrossRef] [PubMed]

12. Cui, Z.; Yang, L.; Cui, Y.; Binks, B.P. Effects of surfactant structure on the phase inversion of emulsions stabilized by mixtures of silica nanoparticles and cationic surfactant. Langmuir 2010, 26, 4717-4724. [CrossRef] [PubMed]

13. Reiber, H.; Köller, T.; Palberg, T.; Carrique, F.; Reina, E.R.; Piazza, R.; Fernandez, F.C. Salt concentration and particle density dependence of electrophoretic mobilities of spherical colloids in aqueous suspension. J. Colloid Interface Sci. 2007, 309, 315-322. [CrossRef] [PubMed]

14. Palberg, T.; Medebach, M.; Garbow, N.; Evers, M.; Fontecha, A.B.; Reiber, H.; Bartsch, E. Electrophoresis of model colloidal spheres in low salt aqueous suspension. J. Phys. Condens. Matter 2004, 16, S4039-S4050. [CrossRef]

15. Belloni, L. Ionic condensation and charge renormalization in colloidal suspensions. Colloids Surfaces A Physicochem. Eng. Asp. 1998, 140, 227-243. [CrossRef]

16. Khademi, M.; Wang, W.; Reitinger, W.; Barz, D.P.J. Zeta Potential of Poly(methyl methacrylate) (PMMA) in Contact with Aqueous Electrolyte-Surfactant Solutions. Langmuir 2017, 33, 10473-10482. [CrossRef]

17. Atkina, R.; Craig, V.S.J.; Wanless, E.J.; Biggs, S. Mechanism of cationic surfactant adsorption at the solid-aqueous interface. Adv. Colloid Interface Sci. 2003, 103, 219-304. [CrossRef]

18. Palberg, T.; Mönch, W.; Bitzer, F.; Piazza, R.; Bellini, T. Freezing transition for colloids with adjustable charge-A test of charge renormalization. Phys. Rev. Lett. 1995, 74, 4555-4558. [CrossRef]

19. Nakamura, Y.; Okachi, M.; Toyotama, A.; Okuzono, T.; Yamanaka, J. Controlled clustering in binary charged colloids by adsorption of ionic surfactants. Langmuir 2015, 31, 13303-13311. [CrossRef]

20. Hunter, T.N. Nonionicsurfactant interactions with hydrophobic nanoparticles: Impacton foam stability. Colloids Surf. A 2009, 347, 81-89. [CrossRef]

21. Cao, H.Y.; Zhang, X.; Ding, B.; Wang, L.; Lu, N. Synergistic action of $\mathrm{TiO}_{2}$ particles and surfactants on the foamability and stabilization of aqueous foams. RSC Adv. 2017, 7, 44972-44978. [CrossRef]

22. Mukherjee, K.; Moulik, S.P.; Mukherjee, D.C. Thermodynamics of micellization of aerosol OT in polar and nnonpolar-solvents-A calorimetric study. Langmuir 1993, 9, 1727-1730. [CrossRef]

23. Strubbe, F.; Beunis, F.; Neyts, K. Determination of the effective charge of individual colloidal particles. J. Colloid Interface Sci. 2006, 301, 302-309. [CrossRef] [PubMed] 
24. Li, Z.X.; Lu, J.R.; Thomas, R.K.; Penfold, J. Neutron reflectivity studies of the adsorption of aerosol-OT at the air-water interface: The structure of the sodium salt. J. Phys. Chem. B 1997, 101, 1615-1620. [CrossRef]

25. Hessinger, D.; Evers, M.; Palberg, T. Independent ion migration in suspensions of strongly interacting charged colloidal spheres. Phys. Rev. E 2000, 61, 5493-5506.

26. Tscharnuter, W.W. Mobility measurements by phase analysis. Appl. Opt. 2001, 40, 3995-4003. [CrossRef] [PubMed]

27. Espinosa, C.E.; Guo, Q.; Singh, V.; Behrens, S.H. Particle charging and charge screening in nonpolar dispersions with nonionic surfactants. Langmuir 2010, 26, 16941-16948. [CrossRef]

28. Garbow, N.; Evers, M.; Palberg, T.; Okubo, T. On the electrophoretic mobility of isolated colloidal spheres. J. Phys. Condens. Matter 2004, 16, 3835-3842. [CrossRef]

29. Strubbe, F.; Beunis, F.; Marescaux, M.; Neyts, K. Charging mechanism in colloidal particles leading to a linear relation between charge and size. Phys. Rev. E 2007, 75, 031405. [CrossRef]

30. Cui, Z.; Cui, Y.; Cui, C.; Chen, Z.; Binks, B.P. Aqueous foams stabilized by in situ surface activation of $\mathrm{CaCO}_{3}$ nanoparticles via adsorption of anionic surfactant. Langmuir 2010, 26, 12567-12574.

(C) 2019 by the authors. Licensee MDPI, Basel, Switzerland. This article is an open access article distributed under the terms and conditions of the Creative Commons Attribution (CC BY) license (http://creativecommons.org/licenses/by/4.0/). 